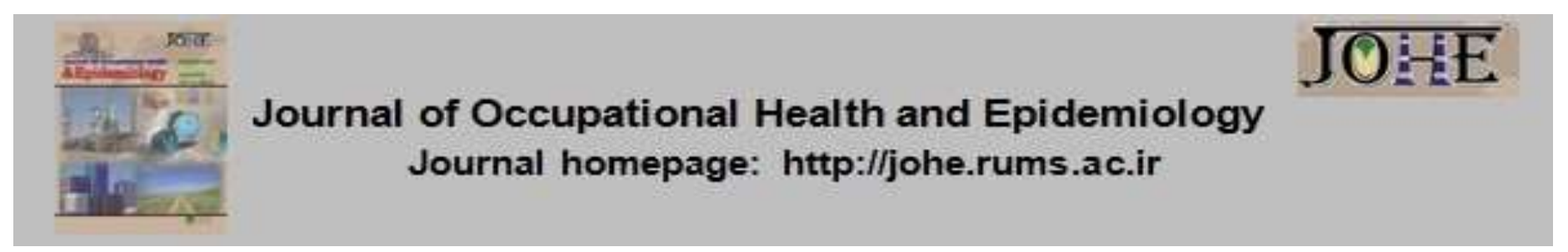

\title{
The effect of mindfulness in motion-based trainings on resiliency, emotion regulation, and job stress
}

\author{
Mohammad Taghi Movassagh ${ }^{1}$, Nasrin Arshadi² $^{*}$, Soodabeh Bassaknejad ${ }^{3}$, Kiomars Beshlideh $^{4}$ \\ 1. PhD Student, Department of Industrial and Organizational Psychology, Shahid Chamran University of Ahvaz, Ahvaz, Iran. \\ 2. Associate Prof., Department of Industrial and Organizational Psychology, Shahid Chamran University of Ahvaz, Ahvaz, Iran. \\ 3. Associate Prof., Department of Clinical Psychology, Shahid Chamran University of Ahvaz, Ahvaz, Iran. \\ 4. Associate Prof., Department of Industrial and Organizational Psychology, Shahid Chamran University of Ahvaz, Ahvaz, Iran.
}

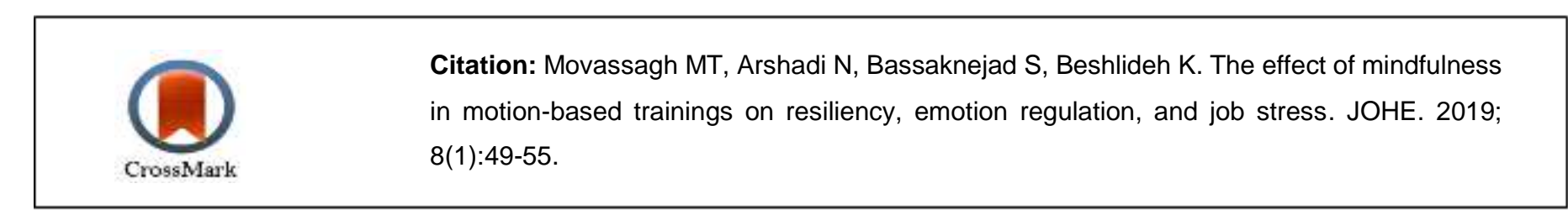

\section{Article Info \\ * Corresponding author: \\ Nasrin Arshadi, \\ E-mail: \\ narshadi@scu.ac.ir}

\section{Article history}

Received: May, 2018

Accepted: Feb, 2019

10.29252/johe.8.1.49

Print ISSN: 2251-8096 Online ISSN: 2252-0902

Peer review under responsibility of Journal of Occupational Health and Epidemiology

\begin{abstract}
Background: Mindfulness can be effective in improving employees' psychological wellbeing. The objective of this research was to examine the effects of mindfulness in motion-based (MIM) trainings on resiliency, emotion regulation, and job stress.

Materials and Methods: The research method was experimental with a pretest-posttest design, a control group, and a follow-up phase. Using the stratified random sampling method, 300 employees were selected from the population. Next, based on the mindfulness questionnaire as well as the inclusion and exclusion criteria, 40 employees were selected as the research sample and were assigned randomly to experimental and control groups (20 employees in each group). The instruments included the mindfulness questionnaire, the resiliency questionnaire, the health and safety executive questionnaire, and the emotion regulation scale. The experimental group received the intervention of mindfulness in motion-based trainings in eight 60-minute sessions, but the control group received no intervention.
\end{abstract}

Results: The results indicated that mindfulness in motion-based trainings improved resiliency significantly at the posttest $(P<0.001, F=22.728)$ and the follow-up phase $(P$ $<0.001, F=25.368)$. The trainings improved reappraisal results at the posttest $(P<0.001$, $F=15.578)$ and the follow-up phase $(P<0.001, F=6.594)$, and also reduced the suppression level at the posttest $(P<0.001, F=27.244)$ and the follow-up phase $(P<0.001$, $F=15.180)$.

Conclusions: The results indicated the positive impact of mindfulness in motion-based trainings. Thus, it is recommended that theses trainings be utilized in the workplace.

Keywords: Mindfulness, Emotion, Job Stress.

\section{Introduction}

Occupational activities occur at the most wakeful times of most people. Putting high emphasis on the work time and energy will culminate in many physical, social, and psychological reflections on employees $(1,2)$. In addition, work can be a source of stress and many concomitant negative outcomes in individuals and organizations $(3,4)$. Job stress is one of the factors affecting employee productivity in every organization. Based on the job demandresources model (JD-R model), occupational stress is defined as an aspect of a job that involves physical and psychological costs to employees (5).
Job stress is one of the major factors that can exert a negative impact on employee performance, increase the probability of physical and psychological damage to employees, and reduce organizational productivity $(6,7)$. In this regard, job stress and resiliency as well as their relationship have been the subjects of many studies. Research shows that resiliency is considered an effective coping style in dealing with job stress (8). Resiliency refers to the capacity of individuals to stay healthy and firm in unfavorable work conditions (9). Emotion regulation can also be considered a coping mechanism in managing stress in high-risk work environments (10). Emotion regulation is defined as 
the conscious or unconscious process of initiating, maintaining, or modifying pleasant or unpleasant emotions (11).

Nevertheless, it is expected that mindfulness trainings be effective in reducing job stress, while improving resiliency and emotional regulation. Mindfulness is defined as the state of consciousness in which a person has a conscious, purposeful, contemporary, and non-judgmental attitude towards his internal and external circumstances (12). Clinical therapists and health researchers utilize mindfulness in treating psychiatric disorders and reducing psychological distress (13-15). Upon the development of this trend in other fields of study, many studies suggest the effectiveness of mindfulness training programs in improving job structures so that the results will include benefits, such as improved productivity and job performance (15-17), with reduced job burnout (19-20).

Against this background, few empirical studies have been conducted in Iran on mindfulness trainings and their effects on work environments. Many studies have been done on the positive effects of mindfulness trainings on non-occupational environments, using students or clinical samples. However, the empirical findings of such studies cannot be generalized to work environments. Therefore, the objective of the present study is to use the modified version of the mindfulness-based stress reduction method introduced by Klatt et al (2015) known as MIM to study the effects of mindfulness trainings in the workplace on a set of psychological and occupational variables in the statistical population of employees. The mindfulness in motion method has been designed in accordance with the time and space constraints of employees in the workplace. Therefore, this method is especially suitable for use in work environments. The distinctions between this method and the mindfulness-based stress reduction method lie in the time compression of the sessions (60 minutes per week), its focus on the individual performance of the pre-recorded practicum of meditations, and the daily sessions of yoga exercises proper for employees (21). Therefore, the present research seeks to answer the question of 'Are mindfulness in motion-based trainings effective in resiliency, emotion regulation, and job stress?'

\section{Materials and Methods}

The present study was an experimental study using a pretest-posttest design, with control and experimental groups, and a follow-up phase (9 weeks later).
The statistical population of this study consisted of the employees of the National Iranian South Oil Company (NISOC) of Ahwaz City in 2017. To select the participants of the research, upon the permission of the company, according to the total number of employees (5000 people), and considering the number of the sample according to Krejcie and Morgan's table (22), 300 employees were selected randomly from the departments of finance, non-industrial operations, production, technical affairs, engineering, procurement, planning, and HR. Next, each department was considered as a category, with the samples selected randomly based on the population size of each category. They were then examined in terms of the Five Facet Mindfulness Questionnaire (FFMQ). Those with scores one standard deviation below the mean and willing to attend training sessions, and based on inclusion and exclusion criteria, 40 employees were selected and assigned randomly (by coin flipping) to experimental and control groups (with 20 people in each of the experimental and control groups). The inclusion criteria of the study were doing daytime work, having a permanent or temporary employment contract, having at least a bachelor's degree, having a minimum of four years of experience, having scores one standard deviation below the mean in the mindfulness questionnaire, and expressing interest and satisfaction in participating in the training sessions. In addition, the exclusion criteria were the use of psychiatric drugs, participation in other training sessions simultaneously, and absence from more than two training sessions. In this study, the following questionnaires were used for data collection:

Five Facet Mindfulness Questionnaire (FFMQ): A 39-item questionnaire was developed by Baer, Smith, Hopkins, Krietemeyer, and Tony in 2006 (23). In this questionnaire, the responses are rated based on a 5-point Likert scale ranging from 1 (never) to 5 (always), expressing the amount of the individual's consent or opposition to each of the phrases, so a higher score indicates more mindfulness. Research findings in Iran show that this questionnaire has already been approved in terms of its validity and reliability. The internal consistency of the questionnaire, resulted from correlation among the components of the questionnaire and the total score, indicated that there was a significant correlation among all components and the total score. In addition, divergent validity showed that there was a significant negative correlation, with the coefficient of 0.21 , between the total score of the questionnaire and that of the experimental avoidance questionnaire (24). 
Resiliency questionnaire: In this study, the ConnerDavidson's (2003) resiliency questionnaire was used to measure resiliency (25), and Mohammadi (2005) adapted it for use in the Iranian society. The questionnaire has 25 items and is rated on the Likert scale (never, rarely, sometimes, often, and always) with the scores being within the range of 1 to 5 . Research findings in Iran showed that this questionnaire had acceptable validity and reliability. The Reliability of this scale has been reported based on the internal consistency method with the Cronbach's alpha of 0.98 and high construct validity (26).

Emotion regulation scale: This scale is made up of 10 items as introduced by Gross and John in 2003 (27) and has two reappraisal (6 items) and suppression (4 items) subscales. The responses are presented based on the Likert scale (7 scores), ranging from 1 (totally disagree) to 7 (totally agree). The Persian version of the scale of 'emotion regulation' is standardized in the Iranian culture. The reliability of this scale has been verified based on the internal consistency method with the Cronbach's alpha of $0 . .^{4}$ to 0.81 , and desirable construct validity (28).

Job stress questionnaire: It is a tool designed by the UK's Occupational Health and Safety Executive (HSE) to measure occupational stress indices. The questionnaire has 35 items with a 5-point Likert scale of never (1), rarely (2), sometimes (3), often (4), and always (5), formed based on the demandcontrol-support model. The revised version was presented by Cousins, MacKay, Clarke, Kelly, Kelly, and McCaig in 2004 (29). The questionnaire consists of the seven components of demand (8 items), control (6 items), peer support (4 items), managerial support (5 items), relationships (4 items), role (4 items), and change ( 3 items). In this study, the total score of job stress has been taken into account. The reliability and validity of the job stress questionnaire have been reported in an Iranian study. The convergent validity showed that there was a significant negative correlation, with a coefficient of 0.48 , between the total score of the questionnaire and that of the general health questionnaire. The reliability of this questionnaire has been reported based on the internal consistency method with the Cronbach's alpha of 0.78 (30).

The participants were told that their responses would remain confidential, so they responded to the self-report tools after their written informed consent was obtained. In addition, they were told that the training sessions would be held in a group to help them improve their psychological status, as a part of the study. Next, having filled out the informed consent form, the participants were enrolled. The mindfulness sessions consisted of eight 60-minute sessions (a session per week), with the sessions held at the Mental Health Center of the National Iranian South Oil Company. The mindfulness in motion-based training in the present study is a modified model based on Kabat-Zinn's mindfulnessbased stress reduction method (31), which is applied to work environments and referred to as mindfulness in motion (MIM) (27). The content of the courses included physical relaxation, meditation practice, yoga practice, body scan, mindful eating, listening to music, self-massage, and constructive discussions about stress management. The exercises were suitable for work environments. In all sessions, relaxing music was played to create a favorable atmosphere for learning. In addition, to involve the participants' minds during the sessions, some questions were provided about weekly topics, and they were invited to share their responses with each other voluntarily. In sessions, emphasis was placed on the awareness of the habit patterns of stress responses and learning more productive behaviors. After the training sessions were completed, the participants responded to the questionnaires of the posttest.

The participants in both experimental and control groups responded to the research tools three times in the pretest, posttest, and the follow-up phase. In order to take account of ethical considerations at the end of the study, the control group received mindfulness trainings in the workplace after data collection in the follow-up phase.

Data analysis was performed using SPSS Statistics 21.0 and the multivariate analysis of covariance method (MANCOVA) at a 0.05 significance level. In addition, to ensure that the research groups were similar in terms of demographic features, the independent t-test, the Mann-Whitney $U$ test, and the Chi-Square test were used.

\section{Results}

The mean and standard deviation of age (year) in the experimental group were 43.40 and 7.80 , respectively; likewise, the mean and standard deviation of age (year) in the control group were 42.25 and 7.94 , respectively. The results of the independent t-test showed that there was no significant difference between the two groups in terms of age $(\mathrm{t}=0.466, \mathrm{sig}=0.644)$. The mean and standard deviation of the work experience (year) in the experimental group were 15.20 and 6.20 , and 14.80 and 6.33 in the control group, respectively. In addition, the results of the independent $t$-test showed that there was no significant difference between the two groups in terms of the work experience $(\mathrm{t}=0.202, \mathrm{sig}=0.841)$. From among the 
participants, $90 \%$ of them were male (18 people in the experimental group and 18 people in the control group), and $10 \%$ of them (4 people) were female ( 2 people in the experimental group and 2 people in the control group). In addition, $92.5 \%$ of the participants were married (19 people in the experimental group and 18 people in the control group), and $7.5 \%$ of them ( 3 people) were single (1 people in the experimental group and 2 people in the control group). The results of the Chi-Square test showed that there was no significant difference between the two groups in terms of marital status (Chi-Square $=0.360, \mathrm{sig}=0.548$ ). Additionally, $70 \%$ (14 people) of the experimental group and 75\% (15 people) of the control group had undergraduate degrees, and others had master's degrees. The results of the Mann-Whitney $U$ test showed that there was no significant difference between the participants in the two groups in terms of the level of education $(U=190$, $s i g=0.727)$.

Table 1 shows the descriptive findings of the research variables in the pretest, posttest, and the follow-up phase. Before performing the multivariate analysis of covariance, its assumptions were examined. The results of the Kolmogorov-Smirnov test showed that research data were normal for all the three test times ( $p>0.05)$. In addition, due to the insignificance of the Levene's test, the homogeneity of the variances of the research variables is established ( $p>0.05)$. Box's M test was used to examine the homogeneity of variance-covariance matrices, and the results showed that the value of Box's M was insignificant. Thus, there was no significant difference between the groups in terms of the variance-covariance matrices ( $p>0.05)$.

Table 1: The mean (M) and standard deviation (SD) of the scores of research variables in the employees of the National Iranian South Oil Company of Ahwaz City in 2017

\begin{tabular}{|c|c|c|c|c|c|c|}
\hline \multirow{3}{*}{ Variable } & \multicolumn{3}{|c|}{ Experimental group $(\mathrm{N}=\mathbf{2 0})$} & \multicolumn{3}{|c|}{ Control group $(\mathrm{N}=20)$} \\
\hline & Pretest & Posttest & Follow-up & Pretest & Posttest & Follow-up \\
\hline & 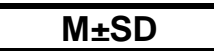 & M土SD & 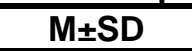 & 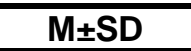 & 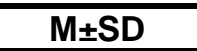 & 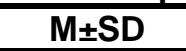 \\
\hline Resiliency & $42.75 \pm 8.20$ & $58.80 \pm 6.31$ & $56.15 \pm 3.58$ & $47.50 \pm 6.01$ & $50.75 \pm 3.74$ & $51.25 \pm 2.75$ \\
\hline Reappraisal & $12.80 \pm 2.76$ & $15.25 \pm 2.31$ & $14.45 \pm 2.60$ & $11.80 \pm 1.47$ & $12.35 \pm 1.63$ & $12.75 \pm 1.65$ \\
\hline Suppression & $11.25 \pm 2.35$ & $7.85 \pm 1.87$ & $7.75 \pm 1.25$ & $10.20 \pm 2.16$ & $12.00 \pm 2.51$ & $10.45 \pm 2.16$ \\
\hline Job stress & $88.10 \pm 16.75$ & $70.30 \pm 5.09$ & $69.55 \pm 5.85$ & $89.00 \pm 6.40$ & $80.80 \pm 4.70$ & $75.75 \pm 4.35$ \\
\hline
\end{tabular}

Table 2 shows that the observed $F$ levels in the posttest and the follow-up phase have been 22.875 and 11.019, respectively, being significant at the 0.001 level. In other words, the results of the Wilks'
Lambda test imply a significant difference between the groups, with a significant difference observed in at least one of the variables in both experimental and control groups.

Table 2: The results of the Multivariate Analysis of Covariance in the employees of the National Iranian South Oil Company of Ahwaz City in 2017

\begin{tabular}{ccccccc}
\hline & Value & F & Hypothesis & Error & P.value & Eta \\
\hline Wilks' Lambda Tes Posttest & 0.253 & 22.875 & 4 & 31 & 0.001 & 0.747 \\
\hline Follow-up & 0.413 & 11.019 & 4 & 31 & 0.001 & 0.587 \\
\hline
\end{tabular}

As table 3 shows, the difference between the mean scores of resiliency was significant in the posttest $(P$ $<0.001, F=22.728$ ) and the follow-up phase ( $P$ $<0.001, F=25.368$ ) after controlling the scores of the pretest in both groups. In addition, the difference between the mean scores of reappraisal in the posttest $(P<0.001, F=15.578)$ and the follow-up phase $(P<0.001, F=6.594)$, and the difference between the mean scores of suppression in the posttest $(P<0.001, F=27.244)$ and the follow-up phase $(P<0.001, F=15.180)$ were significant after controlling the scores of the pretest in both groups. Besides, the difference between the mean scores of job stress in the posttest $(\mathrm{P}<0.001, \mathrm{~F}=28.867)$ and the follow-up phase $(P<0.001, F=12.540)$ was significant after controlling the scores of the pretest in both groups. Based on the information presented in Table 1, it is concluded that mindfulness in motion-based trainings improved resiliency and reappraisal significantly and reduced suppression and job stress significantly. 
Table 3: Tests of Between-Subjects Effects in the employees of the National Iranian South Oil Company of Ahwaz City in 2017

\begin{tabular}{|c|c|c|c|c|c|c|c|c|}
\hline & & Variable & SS & DF & MS & $\mathbf{F}$ & P.Value & Eta \\
\hline \multirow{12}{*}{ Posttest } & \multirow{4}{*}{ Group } & Resiliency & 650.302 & 1 & 650.302 & 22.728 & 0.001 & 0.401 \\
\hline & & Reappraisal & 61.588 & 1 & 61.588 & 15.578 & 0.001 & 0.314 \\
\hline & & Suppression & 145.363 & 1 & 145.363 & 27.244 & 0.001 & 0.445 \\
\hline & & Job stress & 624.941 & 1 & 624.941 & 28.867 & 0.001 & 0.459 \\
\hline & \multirow{4}{*}{ Error } & Resiliency & 972.813 & 34 & 28.612 & & & \\
\hline & & Reappraisal & 134.419 & 34 & 3.954 & & & \\
\hline & & Suppression & 181.408 & 34 & 5.336 & & & \\
\hline & & Job stress & 736.076 & 34 & 21.649 & & & \\
\hline & \multirow{4}{*}{ Total } & Resiliency & 121683 & 40 & & & & \\
\hline & & Reappraisal & 7854 & 40 & & & & \\
\hline & & Suppression & 4299 & 40 & & & & \\
\hline & & Job stress & 230328 & 40 & & & & \\
\hline \multirow{12}{*}{$\begin{array}{c}\text { Follow- } \\
\text { up }\end{array}$} & \multirow{4}{*}{ Group } & Resiliency & 224.867 & 1 & 224.867 & 25.368 & 0.001 & 0.427 \\
\hline & & Reappraisal & 27.914 & 1 & 27.914 & 6.594 & 0.001 & 0.162 \\
\hline & & Suppression & 47.327 & 1 & 47.327 & 15.180 & 0.001 & 0.309 \\
\hline & & Job stress & 351.733 & 1 & 351.733 & 12.540 & 0.001 & 0.269 \\
\hline & \multirow{4}{*}{ Error } & Resiliency & 301.383 & 34 & 8.864 & & & \\
\hline & & Reappraisal & 143.940 & 34 & 4.234 & & & \\
\hline & & Suppression & 106.002 & 34 & 3.118 & & & \\
\hline & & Job stress & 953.664 & 34 & 28.049 & & & \\
\hline & \multirow{4}{*}{ Total } & Resiliency & 115976 & 40 & & & & \\
\hline & & Reappraisal & 7608 & 40 & & & & \\
\hline & & Suppression & 3504 & 40 & & & & \\
\hline & & Job stress & 212516 & 40 & & & & \\
\hline
\end{tabular}

\section{Discussion}

According to the findings of the present study, mindfulness trainings in the workplace are effective in improving employee resiliency, being consistent with the results of other studies $(9,21,32,33)$.

The findings of other studies consistent with the present one show that mindfulness trainings enhance distress tolerance, vigor, and resilience of employees but reduce employee perceived stress $(9,33)$. In addition, some research show that MIM enhances work engagement and resiliency (21), subjective sleep quality, and daytime dysfunction but reduces employee perceived stress (32).

By way of clarification, one can argue that mindfulness trainings in the workplace make an individual return to self, coax them out of the challenges of thoughts and problems into relaxation and flexibility, and increase resiliency. In mindfulness training sessions, individuals learn to be aware of themselves as well as the surrounding environment and conditions, and behave wisely in the workplace when in difficult situations, instead of showing immediate and unpleasant reactions. As a result, they show more resiliency to life difficulties. Mindful people know that pleasant and unpleasant conditions are transient, and that there is no permanent phenomenon. Thus, they cope with impermanent difficult conditions better and show more resiliency $(34,35,36)$. Therefore, individuals receiving mindfulness trainings become more capable of dealing with internal and external stimuli in a direct manner and look at events with a non-judgmental attitude. As a result, there is a positive correlation between receiving mindfulness trainings and the level of employee resiliency (32, 33).

According to the results of the present study, mindfulness trainings in the workplace are effective in improving the emotional regulation of employees and can increase reappraisal and reduce suppression in them, being consistent with the results of past research $(12,15)$.

In addition, based on the research findings, mindfulness interventions are effective in reducing emotional exhaustion and improving job satisfaction (12). Such interventions are also effective in reducing psychological distress, stress, and burnout in employees (15). In explaining this finding, one can say that mindfulness in the workplace involves the skills and techniques by which employees experience a higher degree of consistency and are less affected by the stressors of the work environment. As a result, they will be able to reevaluate their emotional state cognitively and reduce the severity of the perceived stress. In other words, mindfulness trainings in the workplace make employees react less to stressful events. Therefore, as such trainings are associated with relaxation techniques, they will be more relaxed both physically and mentally. In addition, they will reevaluate issues better and focus cognitively on modifying their emotions. In addition, mindfulness trainings in the workplace, including reactions such as acceptance and psychological flexibility, are less likely to make individuals adopt unconventional 
strategies, such as the frequent avoidance of exposure to stressful events (10).

The findings of this study also showed that mindfulness in the workplace is effective in reducing job stress, being consistent with the results of other studies, directly and indirectly $(18,21,30)$. Participants were asked to take a chair, close their eyes, and start loosening and tightening the parts of their bodies. Therefore, stress management skills were taught indirectly in everyday life, and given that one of the major areas of a person's life is their job and work environment, this environment could be full of stressors. Therefore, due to mindfulness trainings in the workplace, the amount of job stress was reduced so that employees were less stressed after learning stress management skills at group meetings and enjoyed a higher degree of psychological well-being (27). The findings of this research were applied to the statistical population of the employees of the National Iranian South Oil Company (NISOC) of Ahwaz City, so in generalizing those findings to other statistical populations and employees of other organizations, one must act cautiously. It is suggested that similar studies be done on the employees of other organizations to get more comprehensive information about the effectiveness of mindfulness in motion-based trainings. Thus, it is suggested that in order of improving skills, such as resiliency and emotion regulation, and for reducing job stress, training courses be run based on mindfulness interventions in the workplace.

\section{Conclusion}

The results indicated the high effectiveness of mindfulness in motion-based trainings in improving resiliency and emotion regulation, and reducing the job stress of employees in the posttest and the follow-up phase. In other words, mindfulness in motion-based trainings, apart from having positive psychological and occupational consequences in the short run, have positive consequences in the long run. The interventions included formal and informal exercises that were done continuously. Therefore, the employees learned after the end of the course to do formal exercises, such as relaxation exercises, with their everyday life influenced informally by participation in mindfulness in motion-based trainings.

\section{Acknowledgement}

This article is an extract of a PhD dissertation on psychology submitted at Shahid Chamran University of Ahvaz. The authors would like to express their sincere gratitude to the staff of the NISOC for their valuable cooperation.
Conflict of interest: None declared.

\section{References}

1- Butts MM, Vandenberg RJ, DeJoy DM, Schaffer BS, Wilson MG. Individual reactions to high involvement work processes: investigating the role of empowerment and perceived organizational support. J Occup Health Psychol 2009; 14(2):122-36.

2- Poursadeghiyan $M$, Moghimian $M$, Amjad RN, Baneshi MM, Yari A, Noroozi M, et al. Effects on job stress on Iranian clinical nurses. Annals of Tropical Medicine and Public Health 2017; 10(4):985-8.

3- Goetzel RZ, Long SR, Ozminkowski RJ, Hawkins K, Wang S, Lynch W. Health, absence, disability, and presenters cost estimates of certain physical and mental health conditions affecting U.S. employers. J Occup Environ Med 2004; 46(4):398-412.

4- Khammar A, Amjad RN, Rohani M, Yari A, Noroozi M, Poursadeghian A, et al. Survey of shift work disorders and occupational stress among nurses: A cross-sectional study. Annals of Tropical Medicine and Public Health 2017; 10(4):978-84.

5- Bakker AB, Demerouti E. The Job DemandsResources model: State of the art. Journal of Managerial Psychology 2007; 22(3):309-28.

6- Selamu M, Thornicroft G, Fekadu A, Hanlon C. Conceptualization of job-related wellbeing, stress and burnout among healthcare workers in rural Ethiopia: a qualitative study. BMC Health Serv Res 2017; 17(1):412.

7- Kang MK, Kang YS, Kim JR, Jeong BG, Park KS, Kam S, et al. The levels of psychosocial stress, job stress and related factors of medical doctors practicing at local clinics. J Prev Med Public Health 2007; 40(2):177-84.

8- Siu OL, Hui CH, Phillips DR, Lin L, Wong TW, Shi K. A study of resiliency among Chinese health care workers: Capacity to cope with workplace stress. J Res Pers 2009; 43(5):770-6.

9- Nila K, Holt DV, Ditzen B, Aguilar-Raab C. Mindfulness-based stress reduction (MBSR) enhances distress tolerance and resilience through changes in mindfulness. Ment Health Prev 2016; 4(1):36-41.

10- Delahaij R, Van Dam K. Coping with acute stress in the military: The influence of coping style, coping self-efficacy and appraisal emotions. Pers Individ Dif 2017; 119:13-8.

11- Gross JJ, Barrett LF. Emotion generation and emotion regulation: one or two depends on your point of view. Emot Rev 2011; 3(1):8-16.

12- Hulsheger UR, Alberts HJ, Feinholdt A, Lang JW. Benefits of mindfulness at work: The role of mindfulness in emotion regulation, emotional exhaustion, and job satisfaction. J Appl Psychol 2013; 98(2):310-25. 
13- Grossman P, Niemann L, Schmidt S, Walach H. Mindfulness-based stress reduction and health benefits: A meta-analysis. J Psychosom Res 2004; 57(1):35-43.

14- Grégoire S, Lachance L. Evaluation of a brief mindfulness-based intervention to reduce psychological distress in the workplace. Mindfulness (NY) 2015; 6(4):836-47.

15- Grégoire S, Lachance L, Taylor G. Mindfulness, mental health and emotion regulation among workers. International Journal of Wellbeing 2015; 5(4):96-119.

16- Gordon WV, Shonin E, Zangeneh M, Griffiths MD. Work-related mental health and job performance: can mindfulness help? Int J Ment Health Addict 2014; 12(2):129-37.

17- Reb J, Narayanan J, Ho ZW. Mindfulness at work: antecedents and consequences of employee awareness and absent-mindedness. Mindfulness (NY) 2015; 6(1):111-22.

18- Chaskalson M. The mindful workplace: developing resilient individuals and resonant organizations with MBSR. 1st ed. Hoboken, New Jersey, United States: Wiley -Blackwell; 2011. P.20-50.

19- Taylor NZ, Robina Millear PM. The contribution of mindfulness to predicting burnout in the workplace. Pers Individ Dif 2016; 89:123-8.

20- Roeser RW, Schonert-Reichl KA, Jha A, Cullen $M$, Wallace L, Wilensky R, et al. Mindfulness training and reductions in teacher stress and burnout: Results from two randomized, waitlistcontrol field trials. J Educ Psychol 2013; 105(3):787-804

21- Klatt M, Steinberg B, Duchemin AM. Mindfulness in Motion (MIM): An onsite Mindfulness Based Intervention (MBI) for chronically high stress work environments to increase resiliency and work engagement. J Vis Exp 2015; 101 :e52359.

22- Krejcie RV, Morgan DW. Determining sample size for research activities. Education and Psychological Measurement 1970; 30:607-10.

23- Baer RA, Smith GT, Hopkins J, Krietemeyer J, Toney $L$. Using self-report assessment methods to explore facets of mindfulness. Assessment 2006; 13(1):27-45.

24- Dehghani M, Esmaeilian N, Akbari $F$, Hassanvand M, Nikmanesh E. Evaluating the psychometric properties and factorial structure of the five dimensional mindfulness questionnaire. Journal of Thought \& Behavior in Clinical Psychology 2014; 9(33):77-87.
25- Connor KM, Davidson JR. Development of a new resilience scale: the Connor-Davidson Resilience Scale (CD-RISC). Depress Anxiety 2003; 18(2):76-82.

26- Mohammadi M. Factors affecting resilience in persons at risk of substance abuse. [PhD thesis]. Tehran: University of Social Welfare and Rehabilitation Sciences; 2006. P.1-60.

27- Gross JJ, John OP. Individual differences in two emotion regulation processes: implications for affect, relationships, and well-being. J Pers Soc Psychol 2003; 85(2):348-62.

28- Mashhadi A, Ghasempour A, Akbari E, IIBeygi R, Hassanzade Sh. The role of anxiety sensitivity and emotion regulation in prediction of social anxiety disorder in students. Knowledge \& Research in Applied Psychology 2013; 14(2):8999.

29- Cousins R, MacKay CJ, Clarke SD, Kelly Ch, Kelly PJ, McCaig RH. Management standards' work-related stress in the UK: practical development. Work \& Stress 2004; 18(2):11336.

30- Azad Marzabadi E, Gholami F. Reliability and validity assessment for the HSE Job Stress Questionnaire. Journal of Behavioral Sciences 2011; 4(4):291-7.

31- Noonan S. Mindfulness-based stress reduction. Can Vet J 2014; 55(2):134-5.

32- Klatt M, Norre Ch, Reader B, Yodice L, White S. Mindfulness in motion: A mindfulness-based intervention to reduce stress and enhance quality of sleep in scandinavian employees. Mindfulness (N Y) 2017; 8(2):481-8.

33- Aikens KA, Astin J, Pelletier KR, Levanovich K, Baase CM, Park YY, et al. Mindfulness goes to work: impact of an online workplace intervention. J Occup Environ Med 2014; 56(7):721-31.

34- Ghasemi-Jobaneh R, Zahrakar K, Hamdami M, Karimi K. Role of spiritual health and mindfulness in psychological capital of students of university of Guilan. Research in Medical Education 2016; 8(2):27-36

35- Ghasemi Jobaneh R, Nazari A, Sanai Zaker B. The effect of mindfulness training on reducing couple burnout of addict's wife. Journal of Research \& Health 2018; 8(6):506-12.

36- Rastgoo N, Herfedost M, Kheyrjoo E. The effectiveness of a group based mindfulness training on teacher's burnout, job satisfaction, and some psychopathological symptom. Journal of Cognitive Strategies in Learning 2017; 4(7):179-98. 